BMJ Open Sport \& Exercise Medicine

\title{
Preventing running-related injuries using evidence-based online advice: the design of a randomised-controlled trial
}

Tryntsje Fokkema, ${ }^{1}$ Robert-Jan de Vos, ${ }^{2}$ John M van Ochten, ${ }^{1}$ Jan AN Verhaar, ${ }^{2}$ Irene S Davis, ${ }^{3}$ Patrick JE Bindels, ${ }^{1}$ Sita MA Bierma-Zeinstra, ${ }^{1}$ Marienke van Middelkoop ${ }^{1}$

To cite: Fokkema T, Vos R-J, van Ochten JM, et al. Preventing running-related injuries using evidencebased online advice: the design of a randomisedcontrolled trial. BMJ Open Sport Exerc Med 2017;3: e000265. doi:10.1136/ bmjsem-2017-000265

Accepted 30 May 2017

\section{CrossMark}

\section{${ }^{1}$ Department of General Practice, Erasmus MC, University Medical Center, Rotterdam, The Netherlands 2Department of Orthopaedics, Erasmus MC, University Medical Center, Rotterdam, The Netherlands ${ }^{3}$ Spaulding National Running Centre, Department of Physical Medicine and Rehabilitation, Harvard Medical School, Cambridge, Massachusetts, USA}

Correspondence to Tryntsje Fokkema; t. fokkema@erasmusmc.nl

\section{ABSTRACT}

Introduction Running-related injuries (RRIs) are frequent and can lead to cessation of health promoting activities. Several risk factors for RRIs have been identified. However, no successful injury prevention programme has been developed so far. Therefore, the aim of the present study is to investigate the effect of an evidence-based online injury prevention programme on the number of RRIs.

Methods and analysis The INSPIRE trial is a randomised-controlled trial with a 3-month follow-up. Both novice and more experienced runners, aged 18 years and older, who register for a running event (distances $5 \mathrm{~km}$ up to $42.195 \mathrm{~km}$ ) will be asked to participate in this study. After completing the baseline questionnaire, participants will be randomised into either the intervention group or control group. Participants in the intervention group will get access to the online injury prevention programme. This prevention programme consists of information on evidence-based risk factors and advices to reduce the injury risk. The primary outcome measure is the number of self-reported RRIs in the time frame between registration for a running event and 1 month after the running event. Secondary outcome measures include the running days missed due to injuries, absence of work or school due to injuries, and the injury location.

Ethics and dissemination An exemption for a comprehensive application is obtained by the Medical Ethical Committee of the Erasmus University Medical Centre Rotterdam, Netherlands. The results of the study will be published in peer-reviewed journals and presented on international congresses.

Trial registration number NTR5998. Pre-results

\section{INTRODUCTION}

Running is a frequently practised sport that is still growing in popularity. In the Netherlands more than 2 million people performed regular running in $2014,{ }^{1}$ which is around $12.5 \%$ of the Dutch population. While running provides many health benefits, the main drawback of running is the fact that runners are prone to musculoskeletal injuries. A systematic review showed that the injury proportions in running vary between $3.2 \%$ and $84.9 \%$, where cross-country runners had lowest number of injuries and novice runners the highest number of injuries. ${ }^{2}$ With the growing population of runners, the number of running-related injuries (RRIs) also increased. Since 2010 the number of RRIs doubled in the Netherlands from about 350.000 RRIs in 2010 to 710.000 RRIs in 2014. ${ }^{1}$ However, the number of RRIs is growing faster than the number of runners. In 2011, the number of RRIs in the Netherlands corresponded to 4.8 injuries per 1000 running hours, in 2014 this number increased to 6.1 injuries per 1000 running hours. ${ }^{1}$

Several studies have been conducted in order to identify risk factors for RRIs, in which many different risk factors have been identified, for example, overweight, a high weekly running distance, a low running cadence and running on outworn shoes. ${ }^{3-6}$ However, the most frequently identified risk factor is a previous injury. ${ }^{7-9}$ Therefore, prevention of this first injury is very important.

An extensive literature search showed that preventive interventions for runners have only been studied in a few randomisedcontrolled trials (table 1). Most of these studies focused on one particular modifiable risk factor for RRIs. Only in a study on the use of motion control shoes a reduction in the number of RRIs was found. ${ }^{10}$ However, these findings contrast with the results of another study on the effects of type of running shoe on pain during running. ${ }^{11}$ The other prevention studies addressing one risk factor did not show a reduction in the number of RRIs. ${ }^{12-16}$ Since the cause of running injuries is multifactorial, the focus on modifying one risk factor is probably not 
Table 1 Randomised controlled trials on the prevention of running-related injuries (RRIs)

\begin{tabular}{|c|c|c|c|c|}
\hline Study & Participants & Intervention & $\begin{array}{l}\text { Outcome } \\
\text { measure }\end{array}$ & Main results \\
\hline $\begin{array}{l}\text { Buist } \\
\text { et } a l^{12}\end{array}$ & $\begin{array}{l}532 \text { novice runners, } \\
\text { enrolled in a beginners' } \\
\text { programme }\end{array}$ & $\begin{array}{l}\text { Graded training programme with an } \\
\text { increase in training volume of no } \\
\text { more than } 10 \% \text { per week }\end{array}$ & $\begin{array}{l}\text { Incidence } \\
\text { of RRls }\end{array}$ & No effect \\
\hline $\begin{array}{l}\text { Bredeweg } \\
\text { et } a l^{14}\end{array}$ & $\begin{array}{l}\text { Healthy participants } \\
\text { enrolled in beginners' 9- } \\
\text { week training programme }\end{array}$ & $\begin{array}{l}\text { 4-week preconditioning training } \\
\text { programme with walking and } \\
\text { hopping exercises }\end{array}$ & $\begin{array}{l}\text { Incidence } \\
\text { of RRls }\end{array}$ & No effect \\
\hline $\begin{array}{l}\text { Malisoux } \\
\text { et } a l^{10}\end{array}$ & 372 recreational runners & $\begin{array}{l}\text { Motion control versus standard } \\
\text { running shoes }\end{array}$ & $\begin{array}{l}\text { Incidence } \\
\text { of RRls }\end{array}$ & $\begin{array}{l}\text { Motion shoes reduced the } \\
\text { number of injuries in runners } \\
\text { with pronating foot type }\end{array}$ \\
\hline $\begin{array}{l}\text { Malisoux } \\
\text { et } a l^{16}\end{array}$ & 535 leisure-time runners & $\begin{array}{l}\text { Standard cushioned running shoes } \\
\text { with different levels of heel-to-toe } \\
\text { drop }\end{array}$ & $\begin{array}{l}\text { Incidence } \\
\text { of RRls }\end{array}$ & No effect \\
\hline $\begin{array}{l}\text { Theisen } \\
\text { et al }\end{array}$ & $\begin{array}{l}247 \text { leisure-time distance } \\
\text { runners }\end{array}$ & $\begin{array}{l}\text { Soft versus hard midsoles in } \\
\text { standard running shoes }\end{array}$ & $\begin{array}{l}\text { Incidence } \\
\text { of RRls }\end{array}$ & No effect \\
\hline $\begin{array}{l}\text { Van } \\
\text { Mechelen } \\
\text { et } a l^{13}\end{array}$ & $\begin{array}{l}421 \text { male recreational } \\
\text { runners }\end{array}$ & $\begin{array}{l}\text { Standardised warm-up, cooldown } \\
\text { and stretching exercises }\end{array}$ & $\begin{array}{l}\text { Incidence } \\
\text { of RRls }\end{array}$ & No effect \\
\hline
\end{tabular}

Search in Pubmed with search terms: (running injury OR running injuries) AND (prevention OR preventing) AND randomised controlled trial. Search performed on 22 December 2016.

the best way to decrease the number of RRIs. A multifactorial approach, in which several risk factors are addressed at the same time, might therefore be more effective.

Therefore, the aim of the present study is to examine the effect of an evidence-based online injury prevention programme on the number of RRIs.

\section{METHODS AND ANALYSIS \\ Study design}

The INSPIRE trial (INtervention Study on Prevention of Injuries in Runners at Erasmus MC) is a randomised-controlled trial with a 3-month follow-up. Recruitment of participants for the INSPIRE trial takes place from October 2016 onwards and data analysis starts in September 2017. A flow chart of the design and follow-up is shown in figure 1 .

This study is funded by the Netherlands Organisation for Health Research and Development (ZonMW) and is performed in collaboration with Golazo, an organisation of large running events in the Netherlands. An exemption for a comprehensive application is obtained by the Medical Ethical Committee of the Erasmus University Medical Center Rotterdam, The Netherlands (MEC-2016-292) and the study is registered in the Dutch Trial Register (NTR5998). All participants will provide electronic informed consent.

\section{Study population}

All runners who register for one of three large running events are potential participants of the study. The running events include the NN City Pier City Run The
Hague $(5 \mathrm{~km}, 10 \mathrm{~km}$ and $21.1 \mathrm{~km})$, NN Marathon Rotterdam $(10.55 \mathrm{~km}$ and $42.195 \mathrm{~km})$ and the Ladies Run Rotterdam (5, 7.5 and $10 \mathrm{~km})$. Runners can register online for these events. For the current study purpose, the runners are asked if they are interested in participating in a study of the Erasmus MC on the prevention of RRIs on the registration form. Contact information of interested runners is sent to the research team. Subsequently, all interested runners will be sent additional online information about the study and, if still interested, will be asked to provide informed consent for the study and fill in the baseline questionnaire.

Both novice and more experienced runners, aged 18 years and older, can participate in this study. Exclusion criteria are no knowledge of the Dutch language and no access to internet and/or email. Additionally, runners that register less than 2 months before the running event will be excluded because the minimum follow-up of all runners is 3 months.

\section{Sample size}

Based on a recent systematic review on incidence of RRIs among a mixed population of long-distance runners, an injury incidence of $16 \%$ is expected in the control group. ${ }^{2}$ Given the $10.9 \%$ injury incidence found in novice runners, ${ }^{17}$ it is estimated that in $14 \%$ of the runners in our population an injury will occur during follow-up. With a risk difference of $5 \%$ (this means a reduction of 90.000 injuries in the Netherlands), 0.05 significance level (one-sided testing) and a power of $80 \%$, a total of 1006 runners should be 


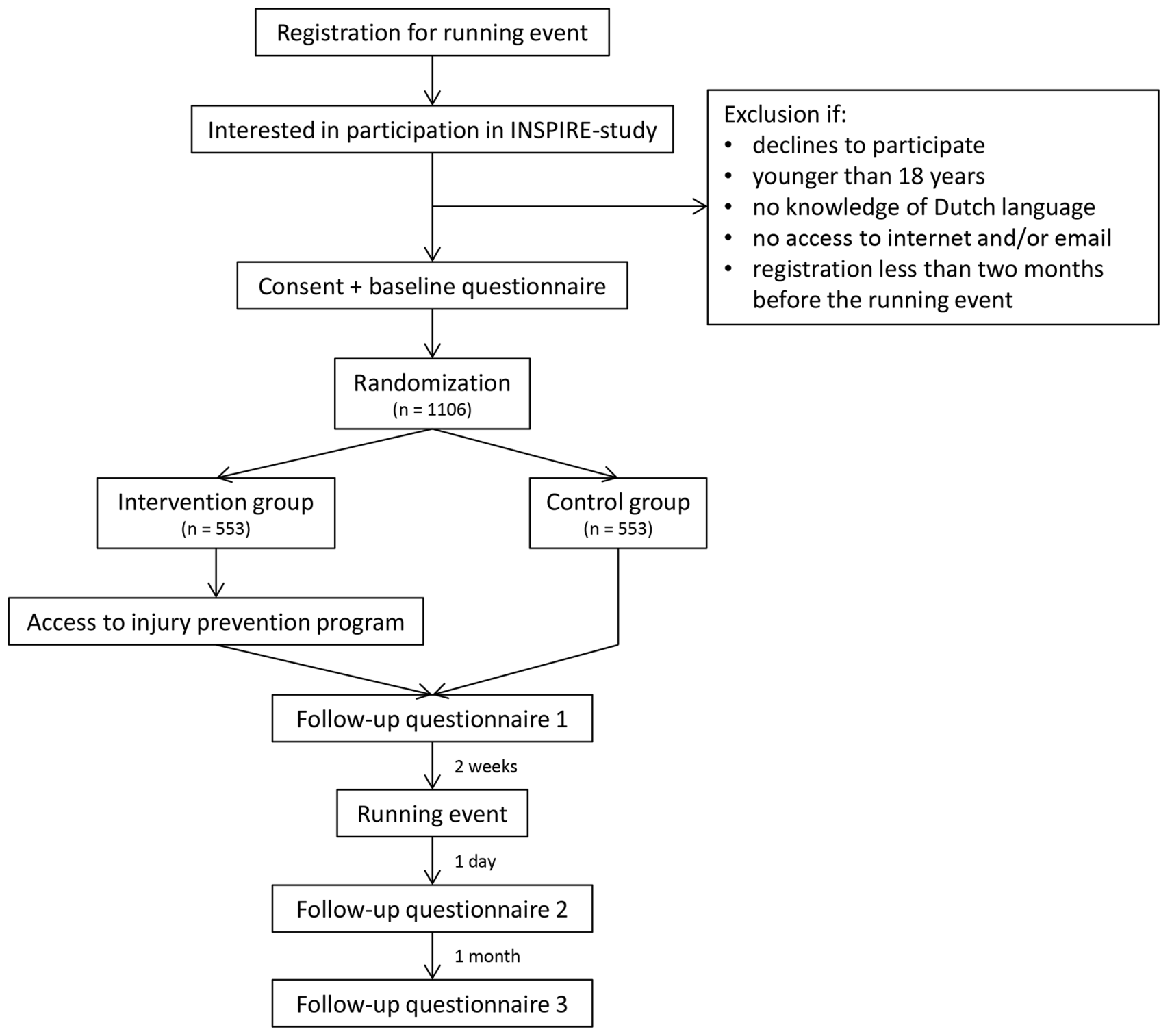

Figure 1 Flow chart of the INSPIRE trial.

included in the analyses to detect a relevant difference in RRIs. Taking a loss to follow-up of $10 \%$ into account, at least 1106 runners (553 in each group) will be included in the trial.

\section{Randomisation}

After completing the baseline questionnaire, the participants will be randomised into either the intervention group or the control group using a computer generated randomisation list with a block size of 10 . The randomisation list is developed by an individual, who is not part of the research team.

\section{Control group}

All participants randomly assigned to the control group will follow their regular preparation for the running event. These participants will not receive additional advices for injury prevention.

\section{Injury prevention programme}

After randomisation, all participants randomly assigned to the intervention group will receive an email with a username and password in order to get access to the online injury prevention programme. This prevention programme can only be accessed with the username and password. The prevention programme is developed by the researchers by means of an extensive literature search and aims to modify evidence-based risk factors for RRIs. The intervention programme is focused on four main topics: personal factors, training factors, equipment and biomechanics. An overview of the topics and advices in the prevention programme is presented in table 2.

The structure of the information about every risk factor is the same and is provided in layman's language. After a short introduction, an overview on the scientific literature is given for the presented risk factor. This is, for example, information on how 
Table 2 Topics and advices in the online injury prevention programme

\begin{tabular}{|c|c|c|c|c|}
\hline & \multicolumn{2}{|l|}{ Risk factors } & \multirow{2}{*}{ Short summary of the advice } & \multirow[t]{2}{*}{ References } \\
\hline & Novice runners & $\begin{array}{l}\text { Experienced } \\
\text { runners }\end{array}$ & & \\
\hline \multirow[t]{4}{*}{$\begin{array}{l}\text { Personal } \\
\text { factors }\end{array}$} & Higher age & Higher age & $\begin{array}{l}\text { Be aware of the higher risk and do not run when } \\
\text { you have any pain }\end{array}$ & 617 \\
\hline & $\begin{array}{l}\text { Overweight or } \\
\text { underweight }\end{array}$ & - & $\begin{array}{l}\text { Adapt a preconditioning phase of partial weight- } \\
\text { bearing sports }\end{array}$ & 391820 \\
\hline & Previous injuries & Previous injuries & $\begin{array}{l}\text { Start building up at a very low level after an injury, } \\
\text { for example, with a training programme for starting } \\
\text { runners }\end{array}$ & $37-926$ \\
\hline & $\begin{array}{l}\text { No experience } \\
\text { with running or } \\
\text { other sports }\end{array}$ & - & Adapt a preconditioning phase of walking & $\begin{array}{l}3471417 \\
18\end{array}$ \\
\hline \multirow[t]{5}{*}{ Training } & Distance & Distance & Run no more than $64 \mathrm{~km}$ per week & 4222326 \\
\hline & Frequency & Frequency & $\begin{array}{l}\text { Train at least two times a week, but not too much. } \\
\text { Search for the optimal frequency }\end{array}$ & $622-2550$ \\
\hline & Overtraining & Overtraining & Consciously apply rest periods using periodisation & 2622 \\
\hline & Surface & Surface & $\begin{array}{l}\text { Perform the majority of the training session on a } \\
\text { soft surface }\end{array}$ & 4 \\
\hline & Stretching & Stretching & $\begin{array}{l}\text { Implement stretching at every training session or } \\
\text { not at all }\end{array}$ & 4 \\
\hline \multirow[t]{2}{*}{ Biomechanics } & Cadence & Cadence & Increase cadence with use of apps & $\begin{array}{l}5 \text { 29-31 51- } \\
56\end{array}$ \\
\hline & Foot landing & Foot landing & $\begin{array}{l}\text { Forefoot strike reduces the risk of RRIs. However, } \\
\text { switching to a forefoot strike increases the risk of } \\
\text { RRIs. Therefore, perform foot muscle exercises } \\
\text { when you want to change to a forefoot strike }\end{array}$ & $57-60$ \\
\hline \multirow[t]{4}{*}{ Equipment } & $\begin{array}{l}\text { Barefoot running } \\
\text { and minimalistic } \\
\text { footwear }\end{array}$ & $\begin{array}{l}\text { Barefoot running } \\
\text { and minimalistic } \\
\text { footwear }\end{array}$ & $\begin{array}{l}\text { Minimalistic shoes might reduce the risk of RRIs. } \\
\text { However, switching to minimalistic shoes increases } \\
\text { the risk of RRIs. Therefore, adapt a habituation } \\
\text { period and use a training schedule when you want } \\
\text { to switch to minimalistic shoes }\end{array}$ & 36576162 \\
\hline & $\begin{array}{l}\text { Neutral, stabilising } \\
\text { and motion- } \\
\text { control shoes }\end{array}$ & $\begin{array}{l}\text { Neutral, stabilising } \\
\text { and motion- } \\
\text { control shoes }\end{array}$ & $\begin{array}{l}\text { Not clear if a certain type of shoe belongs to a } \\
\text { certain type of foot. Do not change the type of } \\
\text { shoes when you have no RRls }\end{array}$ & 101141 \\
\hline & Orthotics/inlays & Orthotics/inlays & $\begin{array}{l}\text { Do not wear orthotics to prevent injuries. Only } \\
\text { consider to wear them when you often have RRIs }\end{array}$ & $42-44$ \\
\hline & $\begin{array}{l}\text { Use of running } \\
\text { shoes }\end{array}$ & $\begin{array}{l}\text { Use of running } \\
\text { shoes }\end{array}$ & $\begin{array}{l}\text { Be aware of the wear pattern of your shoes, } \\
\text { especially when they are older than } 6 \text { months. Use } \\
\text { multiple pairs of shoes }\end{array}$ & 645 \\
\hline
\end{tabular}

RRI, running-related injury.

much higher the chances of sustaining an RRI gets due to the risk factor. When there are contradictory findings in literature, it is also mentioned in this section. Information on, for example, the impact of the risk factor is given, and on uncertainties from literature. Next, the findings from literature are explained, for example, the mechanism on how the risk factor can lead to more RRIs. If necessary, critical notes about studies are also discussed in this section. Finally, the results from literature are translated into practical advices for the runners. These advices are based on interventions that can potentially reduce the risk factor, based on the best available evidence. All advices and information are supported by images, graphics and movies in order to improve the information transfer. All evidence is supported by references and links to other websites, online applications and scientific literature. 
The information in the injury prevention programme is different for novice runners and for experienced runners. A few guidelines will be given to decide whether a runner is considered novice or experienced. In these guidelines novice runners are considered as runners that just started running or have not been running for a long time due to an injury or illness. Experienced runners are considered as runners that have quite some running experience and are able to run shorter distances $(\mathrm{eg}, 5 \mathrm{~km})$ without problems. However, the participants will choose for themselves which category they belong to and will have the possibility to switch between the categories.

\section{Personal factors}

Personal factors are the characteristics of an individual (eg, length, sex and weight). Personal factors that are associated with RRIs include a higher age, overweight and underweight, previous injuries and absence of previous experience with running or other sports. ${ }^{3} 46$ 1819 The associations for weight and absence of previous experience with running or other sports is only studied in novice runners. ${ }^{3} 420$

\section{Training}

Training errors are frequently suggested as the most important cause of injuries. ${ }^{21}$ Several training factors that increase the risk of RRIs have previously been identified. These factors are discussed in the injury prevention programme. The first risk factor that is discussed is the running distance. In several studies it is shown that running more than $64 \mathrm{~km}$ per week increases the risk of RRIs. ${ }^{42}$ Running too many times per week ${ }^{2324}$ and running only once a week increases the risk of RRIs. ${ }^{6}{ }^{25}$ These data suggest that there might be an optimum running frequency for the majority of runners. Also runners that intensively train all year round have a higher chance of sustaining an RRI. ${ }^{22}{ }^{26}$ Therefore, the injury prevention programme contains a section about periodisation. For the novice runners a general advice is provided to plan periods of rest. For the experienced runners a more elaborate explanation of periodisation and its application is given. Also the running surface has influence on the risk of RRIs. It has been shown that running on a hard surface increases the risk of injuries and it is therefore advised to perform the majority of the training sessions on a soft surface. ${ }^{4}$ The last training factor that is discussed in the injury prevention programme is stretching. There still is debate about the use of stretching for injury prevention. ${ }^{27} 28$ However, one thing is clear: occasional stretching increases the risk of RRIs. ${ }^{4}$ Therefore, the participants are advised to stretch at every training session or not at all.

\section{Biomechanics}

In the biomechanics section cadence and foot strike are discussed. There are indications that a higher cadence decreases the risk of injuries, because running with a higher cadence, and consequently with a smaller step length, reduces the forces in the knee and hip joints. ${ }^{5}$ 29-31 Additionally, the different types of foot strike (rearfoot, midfoot and forefoot strike) are discussed. There is some evidence that running with a forefoot strike pattern may reduce injuries ${ }^{32-34}$ due to the reduction in impact forces seen in this footstrike pattern. However, changing to a forefoot strike takes adequate preparation and can result in calf muscle injuries and Achilles tendon overuse injuries if transitioning too quickly. Therefore, if runners would like to transition to a forefoot strike pattern, a training programme developed by Spaulding National Running Centre (Harvard Medical School, Cambridge, Massachusetts, USA) is provided. This training programme contains strengthening exercises for the foot and ankle muscles and a schedule to gradually build up mileage. $^{35}$

\section{Equipment}

This section of the injury prevention programme contains information about running equipment, including shoes and insoles. There are indications that minimalistic shoes reduce the incidence of RRIs. ${ }^{36}$ They have also been shown to increase foot muscle size indicating stronger feet. ${ }^{37}$ However, changing to minimalistic shoes increases the demand on the foot due to the reduced support. They also tend to facilitate a more anterior strike pattern increasing the demand on the calf. If transitioning to a minimal shoe too quickly, foot and ankle injuries can occur. ${ }^{38-40}$ Therefore, the same training programme as for the forefoot strike transition is provided to runners who want to transition to minimal shoes. In this section the correcting types of shoes are also discussed (neutral, cushioning, stabilising and motion control shoes). Because there is debate about the effect of correcting shoes on the number of RRIs, ${ }^{11} 41$ runners are advised not to change the type of shoes when they never have injuries. When a runner is injured often, it could be wise to change the type of shoes. Furthermore, there is no conclusive evidence that wearing inlays has effect on injury prevention. ${ }^{42-44}$ Finally, wearing outworn shoes increases the risk of injuries, ${ }^{6}$ while using multiple pairs of running shoes decreases the risk of RRIs. ${ }^{45}$

\section{Reminders}

All participants in the intervention group will receive monthly reminders about the injury prevention programme by email. Depending on the moment of registration for the study, the participants will receive a maximum of four reminders. These reminders include 
an update on or repetition of one of the topics in the injury prevention programme.

\section{Measurements}

All participants are asked to complete four questionnaires during the study period: at baseline, 2 weeks before the running event for which the runners registered, 1 day after the running event and 1 month after the running event. For all questionnaires the participants will receive an email that contains a secured hyperlink to the questionnaire, using the survey application LimeSurvey. Reminder emails will be used to minimise loss to follow-up and missing data.

\section{Baseline questionnaire}

The baseline questionnaire consists of questions divided in six different sections. General characteristics of the participants include sex, date of birth, length and weight. $^{26}$ The running characteristics section includes questions on running history ("How long are you running already?"), training characteristics during the past week, month, 3 months and year (average running frequency per week, minutes running per week, kilometres per week and average running speed in minutes per $\mathrm{km}$ ), membership of an athletics association (yes/no), use of training schedules, training surface (paved/unpaved and flat/non-flat), types of training (endurance/interval/exercises), number of, type (neutral/pronating/ minimalistic) and advices on running shoes, use of bandages, braces, tape, sport compression socks and inlays, step frequency and landing type (forefoot/midfoot or heel/unknown). ${ }^{26} 46$ The third section consists of questions on previous participation in running events (first participation, average number of participations per year, last participation, distances covered during running events and running shoes used during running events). ${ }^{26}$ Next there is a section on lifestyle, including current smoking (yes/no), alcohol consumption (number of glasses per week) and the Short Questionnaire to Assess Health-enhancing Physical Activity (SQUASH). ${ }^{46}{ }^{47}$ The SQUASH is a validated questionnaire that can be used to evaluate the health-enhancing physical activity in large populations. ${ }^{47} 48$ The fifth section includes RRIs. The participants will be asked about RRIs in the past year ("Did you suffer an RRI during the past 12 months?"), the injured structures, the onset of the injury (sudden/gradually), diagnosis and if they still suffer this injury. ${ }^{26} 46$ The last section includes other health complaints. The participants will be asked if they have health complaints that are not related to running (yes/no) and if yes, which health complaints. $^{26}$

\section{Follow-up questionnaires}

All follow-up questionnaires contain a section on RRIs. First, participants will be asked about RRIs they already had when they filled in the previous questionnaires (injured structures and the diagnosis). The next questions include new RRIs, that developed after filling in the previous questionnaire. The questions are on the injured structure, the onset of the injury (sudden/ gradually), if it is a recurrent injury (yes/no), type of injury (bruise/muscle injury or tendon injury/sprain/ distortion/ligament injury/bone fracture/joint dislocation/cartilage or meniscus injury/nerve entrapment/ unknown) and the diagnosis, and on the treatment (including medication) and the cause of the injury. ${ }^{46}$ Next there are questions on pain due to the RRI $(0-10$ visual analog scale) during running and rest in the past week, ability to perform activities of daily living in the first week after the injury and in the past week, absence from work or school due to the injury, and the duration of and recovery from the injury. ${ }^{46}{ }^{49}$ Also the influence of the injury on running will be asked: limitations in running distance, speed, duration or frequency due to the injury, if they resumed running already and if they plan to/did run the event they registered for. ${ }^{49}$

Additionally, the first follow-up questionnaire contains questions about the preparation for the running event. Participants in the intervention group will also receive questions on the actual use of the injury prevention programme in all follow-up questionnaires. These questions focus on which topics of the intervention programme (personal factors, training factors, biomechanics and equipment) the participants read, which advices they used and for how many weeks they used these advices. In the last follow-up questionnaire the participants in the control group will be asked if they used any injury prevention measures.

\section{Outcome measures}

The primary outcome measure is the number of RRIs in both the intervention and control groups in the period between the moment of registration for the INSPIRE trial and 1 month after the running event they registered for. In this study an RRI is established if one or more of the following criteria are met: ${ }^{17} 46$

1. An injury of the muscles, joints, tendons and/or bones in the lower back or lower extremities (hip, groin, thigh, knee, leg, ankle, foot and toes) that is caused by running.

2. The injury is severe enough to cause a reduction in running distance, speed, duration or frequency for at least 1 week.

3. The injury leads to a visit to a doctor and/or physiotherapist.

4. Medication is necessary to reduce symptoms as a result of the injury.

Secondary outcome measures include the running days missed due to injuries, absence of work or school due to injuries, and the location of the injury. 


\section{Statistical analyses}

Descriptive statistics and their corresponding SD and frequency distributions will be calculated for all variables. Consistent with the CONSORT statement, an intention-to-treat analysis will be performed. Missing data (if more than 5\%) will be completed using a multiple imputation procedure. Injury incidence rates (IIRs) will be calculated for all runners and for the intervention and control groups separately. Also the IIRs for male/female and novice/ experienced runners will be calculated separately. For each IIR, a 95\% CI will be calculated assuming Poisson errors. The IIRs of the intervention and control groups will be compared by calculating the difference with the $95 \%$ CI. Since no difference in distribution between the intervention and control groups is expected, ORs will be calculated using univariate logistic regression. Significance of the ORs will be tested with a Mantel-Haenszel test, with a significance level of $5 \%$. Additionally, effect modification per important subgroup (eg, male/female, novice/experienced and per running distance) will be performed. Also adjusted analysis for main risk factors (eg, age, body mass index and earlier injuries) will be done. The same analyses will be performed for the five most frequent specific injuries separately.

\section{DISCUSSION}

Although RRIs are a major problem among runners, ${ }^{2}$ no effective injury prevention programme has been developed yet. In the present study, the effectiveness of an evidence-based online injury prevention programme will be examined. The prevention programme will be tested in a large and mixed population of runners, which makes it possible to extensively examine the efficacy of the prevention programme. It might also be possible to compare the efficacy in different subgroups of runners (eg, novice/experienced, male/female and different running distances). If the injury prevention programme proves to be successful, it can be implemented in a large group of runners, for example, as a standard procedure at the registration for running events. This can easily be done, because the prevention programme is on a website and can therefore be easily spread among runners. Furthermore, the programme is aimed at different types of runners and is therefore suitable for all participants of running events.

A limitation of the current study is that there is no control over and insight in the use of the injury prevention programme. This is partly solved by the questions about the use of the prevention programme in the follow-up questionnaires for the intervention group. These questions give some insight in who read the prevention programme and used which part of the programme. Furthermore, in case of a future implementation of the prevention programme there will be no control over the use of the prevention programme as well and therefore will the current study give a realistic view of possible future use of the injury prevention programme. Another limitation of this study is that self-reported injuries are used. With selfreported injuries there is no uniformity in when pain is considered as an injury or not. This is partly solved by providing the participants with a clear definition of RRI. Another disadvantage of self-reported injuries is that there often is no diagnosis of the injury or that the runner diagnosed himself or herself.

In conclusion, the INSPIRE trial is the first randomised controlled prevention trial that examines the effectiveness of an evidence-based online advice on reduction of RRIs.

\section{Ethics and dissemination}

The INSPIRE trial will be performed in accordance with the Declaration of Helsinki. Before participation, elaborated information about the study will be sent to potential participants and the participants will have the possibility to ask questions through phone or email. All participants will be asked to give electronic informed consent before filling in the baseline questionnaire. An exemption for a comprehensive application is obtained by the Medical Ethical Committee of the Erasmus University Medical Center Rotterdam, Netherlands (MEC2016-292). The results of the study will be communicated through articles in peer-reviewed journals and on international scientific congresses. The participants will also be informed about the results of the study. If the investigated prevention programme proves to be successful, it can be implemented in a large and diverse group of runners.

Contributors R-JdV and MvM wrote the medical ethical approval application. TF wrote the article, which is based on the funding application written by MvM and R-JdV. The trial was coordinated by MvM.

Funding This work was supported by the Netherlands Organisation for Health Research and Development (ZonMW), grant number 536001001.

Competing interests None declared.

Ethics approval Medical Ethical Committee of the Erasmus University Medical Center Rotterdam, Netherlands.

Provenance and peer review Not commissioned; externally peer reviewed.

Open Access This is an Open Access article distributed in accordance with the Creative Commons Attribution Non Commercial (CC BY-NC 4.0) license, which permits others to distribute, remix, adapt, build upon this work noncommercially, and license their derivative works on different terms, provided the original work is properly cited and the use is non-commercial. See: http:// creativecommons.org/licenses/by-nc/4.0/

(c) Article author(s) (or their employer(s) unless otherwise stated in the text of the article) 2017. All rights reserved. No commercial use is permitted unless otherwise expressly granted. 


\section{REFERENCES}

1 Veiligheid NL. Hardloopblessures Blessurecijfers 2014. 2016 https:// www.veiligheid.nl/.ibmmodres/domino/OpenAttachment/veiligheid/ website.nsf/DEB699ADFF9CB26CC1257FCB0027D759/asset/ Cijfersfactsheet\%20Hardlopen\%202014.pdf (accessed 10 May 2017

2 Kluitenberg B, van Middelkoop M, Diercks R, et al. What are the differences in Injury Proportions between different populations of runners? A systematic review and Meta-Analysis. Sports Med 2015;45:1143-61.

3 Buist I, Bredeweg SW, Bessem B, et al. Incidence and risk factors of running-related injuries during preparation for a 4-mile recreational running event. Br J Sports Med 2010;44:598-604.

4 Macera CA, Pate RR, Powell KE, et al. Predicting lower-extremity injuries among habitual runners. Arch Intern Med 1989;149:2565-8.

5 Schubert AG, Kempf J, Heiderscheit BC. Influence of stride frequency and length on running mechanics: a systematic review. Sports Health 2014;6:210-7.

6 Taunton JE, Ryan MB, Clement DB, et al. A prospective study of running injuries: the Vancouver Sun Run "In Training" clinics. $\mathrm{Br} J$ Sports Med 2003;37:239-44.

7 van der Worp MP, ten Haaf DS, van Cingel R, et al. Injuries in runners; a systematic review on risk factors and sex differences. PLoS One 2015;10:e0114937.

8 Saragiotto BT, Yamato TP, Hespanhol Junior LC, et al. What are the main risk factors for running-related injuries? Sports Med 2014;44:1153-63.

9 van Gent RN, Siem D, van Middelkoop M, et al. Incidence and determinants of lower extremity running injuries in long distance runners: a systematic review. Br J Sports Med 2007;41:469-80.

10 Malisoux L, Chambon N, Delattre N, et al. Injury risk in runners using standard or motion control shoes: a randomised controlled trial with participant and Assessor blinding. Br J Sports Med 2016;50:481-7.

11 Ryan MB, Valiant GA, McDonald K, et al. The effect of three different levels of footwear stability on pain outcomes in women runners: a randomised control trial. Br J Sports Med 2011;45:715-21.

12 Buist I, Bredeweg SW, van Mechelen W, et al. No effect of a graded training program on the number of running-related injuries in novice runners: a randomized controlled trial. Am J Sports Med 2008;36:33-9.

13 van Mechelen W, Hlobil $\mathrm{H}$, Kemper $\mathrm{HC}$, et al. Prevention of running injuries by warm-up, cool-down, and stretching exercises. Am J Sports Med 1993;21:711-9.

14 Bredeweg SW, Zijlstra S, Bessem B, et al. The effectiveness of a preconditioning programme on preventing running-related injuries in novice runners: a randomised controlled trial. $\mathrm{Br} J$ Sports Med 2012;46:865-70.

15 Theisen D, Malisoux L, Genin J, et al. Influence of midsole hardness of standard cushioned shoes on running-related injury risk. $\mathrm{Br} J$ Sports Med 2014;48:371-6.

16 Malisoux L, Chambon N, Urhausen A, et al. Influence of the Heel-toToe drop of standard cushioned running shoes on Injury risk in Leisure-Time runners: a randomized controlled trial with 6-month follow-up. Am J Sports Med 2016;44:2933-40.

17 Kluitenberg B, van Middelkoop M, Smits DW, et al. The NLstart2run study: incidence and risk factors of running-related injuries in novice runners. Scand J Med Sci Sports 2015;25:e515-23.

18 Taunton JE, Ryan MB, Clement DB, et al. A retrospective casecontrol analysis of 2002 running injuries. Br J Sports Med 2002;36:95-101.

19 van der Worp H, Vrielink JW, Bredeweg SW. Do runners who suffer injuries have higher vertical ground reaction forces than those who remain injury-free? A systematic review and meta-analysis. $\mathrm{Br} \mathrm{J}$ Sports Med 2016;50:450-7.

20 Buist I, Bredeweg SW, Lemmink KA, et al. Predictors of runningrelated injuries in novice runners enrolled in a systematic training program: a prospective cohort study. Am J Sports Med 2010;38:273-80.

21 Nielsen RO, Buist I, Sørensen $\mathrm{H}$, et al. Training errors and running related injuries: a systematic review. Int $J$ Sports Phys Ther 2012;7:58-75.

22 Walter SD, Hart LE, Mclntosh JM, et al. The Ontario cohort study of running-related injuries. Arch Intern Med 1989;149:2561-4.

23 Jacobs SJ, Berson BL. Injuries to runners: a study of entrants to a 10,000 meter race. Am J Sports Med 1986;14:151-5.

24 McKean KA, Manson NA, Stanish WD. Musculoskeletal injury in the masters runners. Clin J Sport Med 2006;16:149-54.

25 Malisoux L, Nielsen RO, Urhausen A, et al. A step towards understanding the mechanisms of running-related injuries. J Sci Med Sport 2015;18:523-8.
26 Van Middelkoop M, Kolkman J, Van Ochten J, et al. Risk factors for lower extremity injuries among male marathon runners. Scand J Med Sci Sports 2008;18:691-7.

27 Hartig DE, Henderson JM. Increasing hamstring flexibility decreases lower extremity overuse injuries in military basic trainees. Am J Sports Med 1999;27:173-6.

28 Pope R, Herbert R, Kirwan J. Effects of ankle dorsiflexion range and pre-exercise calf muscle stretching on injury risk in Army recruits. Aust J Physiother 1998;44:165-72.

29 Hobara H, Sato T, Sakaguchi M, et al. Step frequency and lower extremity loading during running. Int J Sports Med 2012;33:310-3.

30 Lieberman DE, Warrener AG, Wang J, et al. Effects of stride frequency and foot position at landing on braking force, hip torque, impact peak force and the metabolic cost of running in humans. $J$ Exp Biol 2015;218:3406-14.

31 Hafer JF, Brown AM, deMille P, et al. The effect of a cadence retraining protocol on running biomechanics and efficiency: a pilot study. J Sports Sci 2015;33:724-31.

32 Cheung RT, Davis IS. Landing pattern modification to improve patellofemoral pain in runners: a case series. J Orthop Sports Phys Ther 2011;41:914-9.

33 Daoud Al, Geissler GJ, Wang F, et al. Foot strike and injury rates in endurance runners: a retrospective study. Med Sci Sports Exerc 2012;44:1325-34.

34 Diebal AR, Gregory R, Alitz C, et al. Forefoot running improves pain and disability associated with chronic exertional compartment syndrome. Am J Sports Med 2012;40:1060-7.

35 Davis IS. The re-emergence of the minimal running shoe. J Orthop Sports Phys Ther 2014;44:775-84.

36 Tam N, Astephen Wilson JL, Noakes TD, et al. Barefoot running: an evaluation of current hypothesis, future research and clinical applications. Br J Sports Med 2014;48:349-55.

37 Chen TL, Sze LK, Davis IS, et al. Effects of training in minimalist shoes on the intrinsic and extrinsic foot muscle volume. Clin Biomech 2016;36:8-13.

38 Giuliani J, Masini B, Alitz C, et al. Barefoot-simulating footwear associated with metatarsal stress injury in 2 runners. Orthopedics 2011;34:e320-3.

39 Ridge ST, Johnson AW, Mitchell UH, et al. Foot bone marrow edema after a 10-wk transition to minimalist running shoes. Med Sci Sports Exerc 2013;45:1363-8.

40 Salzler MJ, Bluman EM, Noonan S, et al. Injuries observed in minimalist runners. Foot Ankle Int 2012;33:262-6.

41 Nielsen RO, Buist I, Parner ET, et al. Foot pronation is not associated with increased injury risk in novice runners wearing a neutral shoe: a 1-year prospective cohort study. Br J Sports Med 2014;48:440-7.

42 Mattila VM, Sillanpää PJ, Salo T, et al. Can orthotic insoles prevent lower limb overuse injuries? A randomized-controlled trial of 228 subjects. Scand J Med Sci Sports 2011;21:804-8.

43 Franklyn-Miller A, Wilson C, Bilzon J, et al. Foot orthoses in the prevention of injury in initial military training: a randomized controlled trial. Am J Sports Med 2011;39:30-7.

44 Leppänen M, Aaltonen S, Parkkari J, et al. Interventions to prevent sports related injuries: a systematic review and meta-analysis of randomised controlled trials. Sports Med 2014;44:473-86.

45 Malisoux L, Ramesh J, Mann R, et al. Can parallel use of different running shoes decrease running-related injury risk? Scand J Med Sci Sports 2015;25:110-5.

46 Kluitenberg B, van Middelkoop M, Diercks RL, et al. The NLstart2run study: health effects of a running promotion program in novice runners, design of a prospective cohort study. BMC Public Health 2013;13:685.

47 Wendel-Vos GC, Schuit AJ, Saris WH, et al. Reproducibility and relative validity of the short questionnaire to assess health-enhancing physical activity. J Clin Epidemiol 2003;56:1163-9.

48 de Hollander EL, Zwart L, de Vries SI, et al. The SQUASH was a more valid tool than the OBiN for categorizing adults according to the dutch physical activity and the combined guideline. J Clin Epidemiol 2012;65:73-81.

49 Van Middelkoop M, Kolkman J, Van Ochten J, et al. Prevalence and incidence of lower extremity injuries in male marathon runners. Scand J Med Sci Sports 2008;18:140-4.

50 Kluitenberg B, van der Worp $\mathrm{H}$, Huisstede BM, et al. The NLstart2run study: training-related factors associated with running-related injuries in novice runners. J Sci Med Sport 2016;19:642-6.

51 Clarke TE, Cooper LB, Hamill CL, et al. The effect of varied stride rate upon shank deceleration in running. J Sports Sci 1985;3:41-9.

52 Derrick TR, Hamill J, Caldwell GE. Energy absorption of impacts during running at various stride lengths. Med Sci Sports Exerc 1998;30:128-35. 
53 Heiderscheit BC, Chumanov ES, Michalski MP, et al. Effects of step rate manipulation on joint mechanics during running. Med Sci Sports Exerc 2011;43:296-302.

54 Mercer JA, Devita P, Derrick TR, et al. Individual effects of stride length and frequency on shock attenuation during running. Med $\mathrm{Scl}$ Sports Exerc 2003;35:307-13.

55 Seay J, Selbie WS, Hamill J. In vivo lumbo-sacral forces and moments during constant speed running at different stride lengths. $J$ Sports Sci 2008;26:1519-29.

56 Morin JB, Samozino P, Zameziati K, et al. Effects of altered stride frequency and contact time on leg-spring behavior in human running. $J$ Biomech 2007;40:3341-8.

57 Lieberman DE, Venkadesan M, Werbel WA, et al. Foot strike patterns and collision forces in habitually barefoot versus shod runners. Nature 2010;463:531-5.
58 Giandolini M, Horvais N, Rossi J, et al. Foot strike pattern differently affects the axial and transverse components of shock acceleration and attenuation in downhill trail running. J Biomech 2016;49:1765-71.

59 Davis IS, Bowser BJ, Mullineaux DR. Greater vertical impact loading in female runners with medically diagnosed injuries: a prospective investigation. Br J Sports Med 2016;50:887-92.

60 Zadpoor AA, Nikooyan AA. The relationship between lower-extremity stress fractures and the ground reaction force: a systematic review. Clin Biomech 2011;26:23-8.

61 Ryan M, Elashi M, Newsham-West R, et al. Examining injury risk and pain perception in runners using minimalist footwear. Br J Sports Med 2014;48:1257-62.

62 Bonacci J, Saunders PU, Hicks A, et al. Running in a minimalist and lightweight shoe is not the same as running barefoot: a biomechanical study. Br J Sports Med 2013;47:387-92. 